\title{
Insulin-Like Growth Factor-I Binds in the Inner Plexiform Layer and Circumferential Germinal Zone in the Retina of the Goldfish
}

\author{
SHAYNE-E MILE M. BOUCHER ${ }^{3}$ AND PETER F. HITCHCOCK ${ }^{1,2,3 *}$ \\ 1Department of Ophthalmology, The University of Michigan, Ann Arbor, Michigan 48105 \\ ${ }^{2}$ Department of Anatomy and Cell Biology, The University of Michigan, \\ Ann Arbor, Michigan 48105 \\ ${ }^{3}$ The Neuroscience Program, The U niversity of Michigan, Ann Arbor, Michigan 48105
}

\begin{abstract}
Results of the previous study suggest that insulin-related peptides regulate proliferation of retinal progenitors in the adult goldfish. Because of their known roles in retinal neurogenesis, we have chosen to focus future studies on insulin-like growth factor I (IGF-I) and the IGF-I receptor. In the study described here, we characterized the spatial distribution and specificity of IGF-I binding sites in the retina of the adult goldfish by performing receptor-binding autoradiography with [125|]-IGF-I alone and with unlabeled IGF-I-related molecules (IGF-I, I GF -II, insulin, and des-[1-3]-IGF-I) as competitive inhibitors of [125I ]-I GF-I binding. The results of these experiments show that I GF-I binds in two locations in the retina of the adult goldfish, within the inner plexiform layer of the differentiated retina and the circumferential germinal zone. The competition experiments suggest that [125I ]-IGF-I binds at sites specific for IGF-I, and that both IGF-I receptors and IGF-I binding proteins are present in the retina. J. Comp. Neurol. 394:395-401, 1998.11998 Wiley-Liss, Inc.
\end{abstract}

Indexing terms: teleost fish; autoradiography; growth factors; growth factor receptors; IGF-I

Insulin-like growth factor 1 (IGF-I) is an evolutionarily ancient and highly conserved single-chain polypeptide, structurally related to proinsulin (see Thorndyke et al., 1989; Chan et al., 1992; Drakenberg et al., 1993; Reinecke et al., 1993). IGF-I and the IGF-I receptor (IGF-IR) are expressed in most developing organs and tissues, where they act as growth-promoting molecules (J ones and Clemmons, 1995). Although originally thought to be synthesized only in the liver as the endocrine mediator of growth hormone (hence its early name, somatomedin), it is now known that I GF -I can act independent of growth hormone and regulate local cellular function in both a paracrine and autocrine manner. The IGF-IR is a cell-surface, tyrosine kinase receptor that shares structural homology with the insulin receptor. The IGF-IR is expressed widely in the developing central nervous system (de Pablo and de la Rosa, 1995) and is thought to mediate the activity of both IGF-I and IGF-II (D'Ercole et al., 1996). The biological activity of IGF-I in both the developing and adult brain is regulated in a complex manner by a family of synchronously expressed IGF-binding proteins (IGF-BPS). These proteins modulate the bioavailability of I GF $-I$ and mediate its interaction with the IGF-IR (J ones and Clemmons, 1995).
In the previous study (Boucher and Hitchcock, 1998), we showed that in vitro insulin-related molecules stimulate proliferation of retinal progenitors in the adult goldfish. Based upon the ubiquitous presence of the family of I GF-I molecules in the brain and retina (e.g., Lee et al., 1992; Schoen et al., 1992; Yang et al., 1993; de la Rosa et al., 1994; Hernádez-Sánchez et al., 1995; Mack et al., 1995; Richardson et al., 1995; Calvaruso et al., 1996; F rade et al., 1996; Leibush et al., 1996), we hypothesized that IGF-I and the IGF-IR are expressed in the retina of the goldfish and together regulate the mitotic activity of the retinal progenitors within the circumferential germinal zone (CGZ).

As one test of this hypothesis, we characterized the spatial distribution and specificity of IGF-I-binding sites

Grant sponsor: NIH; Grant numbers: EY07060 and EY07003 (COREGrant).

*Correspondence to: Peter Hitchcock, Ph.D., W.K. Kellogg Eye Center, University of Michigan, 1000 Wall Street, Ann Arbor, MI 48105.

E-mail: peterh@umich.edu

Received 18 August 1997; Revised 23 December 1997; Accepted 30 December 1997 
by using receptor binding and emulsion autoradiography with iodonated IGF-I ([125I] ]-IGF-I) alone and in combination with the unlabeled competitive inhibitors, IGF-I, IGF-II , insulin, and des-(1-3)-IGF-I. Quantitative analysis of the autoradiographic slides revealed that IGF-I binds within the inner plexiform layer (IPL) of the differentiated retina and, consistent with our hypothesis, to the retinal progenitors within the CGZ. These data, and those of the previous paper (Boucher and Hitchcock, 1998), suggest that, in the retina of the adult goldfish, IGF-I and its receptor have dual roles, regulating yet-to-be-identified cellular processes in the mature retina and regulating proliferation of retinal progenitors within the CGZ.

Portions of these data presented here were reported in preliminary form (Boucher and Hitchcock, 1996).

\section{MATERIALS AND METHODS Animals}

J uvenile goldfish (Carassi us auratus), 3-4 cm standard length, were purchased from local pet stores and housed for at least one week before performing experiments. Prior to surgery and euthanasia, fish were anesthetized in tricaine methanesulfonate (MS222, Sigma, St. Louis, MO). All animals were killed by exsanguination. All animal protocols used in this study were approved by the University of Michigan Committee for the Use and Care of Animals.

\section{Preparation of eyecups}

Eyecups used for [125/]-IGF-I binding were prepared similarly to those used in the organ culture experiments (Boucher and Hitchcock, 1998). Goldfish were anesthetized in tricaine methanesulfonate (MS222), and their eyes were removed. Fish were then killed by exsanguination. Eyes weretransferred to a petri dish filled with phosphatebuffered saline and the lens, cornea, and part of the iris epithelium were removed. The vitreous was briefly permeabilized with digestive enzymes $(0.25 \mathrm{mg} / \mathrm{ml}$ collagenase and $1.0 \mathrm{mg} / \mathrm{ml}$ hyaluronidase), rinsed, and placed in a holding bath containing PBS until all the eyecups were prepared.

\section{[125I]-IGF-I binding experiments}

For these experiments, we used a modification of a previously published protocol (Bassnett and Beebe, 1990). For each eyecup, excess phosphate buffered saline(PBS) in the vitreal chamber was removed and replaced with a $10 \mu \mathrm{l}$ drop of the incubation medium, Media 199 (M 199; Sigma), which contained either [125I]-IGF-I alone (50 nM stock solution reconstituted in $100 \mu \mathrm{M}$ acetic acid, at a specific activity of $74 \mathrm{TBq} / \mathrm{mmol}$; purchased from Amersham, Arlington Heights, IL) or [125I]-IGF-I and an unlabeled I GF-I-related peptide as a competitive inhibitor of binding. A minimum of three eyecups were used per condition; five conditions were tested: 1) $5 \mathrm{nM}$ [ $\left.{ }^{125 I}\right]-\mathrm{IGF}-\mathrm{I}$ alone, 2) $5 \mathrm{nM}$ [125] ]-IGF-I plus 500 nM I GF-I (recombinant human, Austral Biologicals, San Ramon, CA), 3) 5 nM [ ${ }^{125}$ ] ]-IGF-I plus 500 nM IGF-II (recombinant human, R \& D Systems, Minneapolis, MN), 4) $5 \mathrm{nM}$ [125] -IGF-I plus $500 \mathrm{nM}$ insulin (bovine, Sigma) or 5) $5 \mathrm{nM}$ [125 I ]-IGF-I plus $150 \mathrm{nM}$ des-(1-3)-IGF-I (recombinant human, Gro-Pep, Adelaide, $\mathrm{SA}$, Australia). All eyecups were incubated at $4^{\circ} \mathrm{C}$ in a humidified chamber for 5 hours.
At the conclusion of the incubation, the media in the vitreous cavity was removed, and the eyecups were rinsed $2 \times 5$ minutes in ice-cold phosphate-buffered saline, to wash off unbound [125I]-IGF-I. Eyecups were then fixed overnight in 2\% glutaraldehyde in $0.05 \mathrm{M}$ phosphate buffer (pH 7.4) at $4^{\circ} \mathrm{C}$. After fixation, the eyecups were rinsed twice in PBS, cut in half along the dorsonasalventrotemporal axis, dehydrated in a graded series of alcohol, rinsed in propylene oxide and infiltrated with Polybed 812. Eyecups were then placed into molds with fresh Polybed 812 , and polymerized overnight at $60^{\circ} \mathrm{C}$.

\section{Sectioning and emulsion autoradiography}

Eyecups were sectioned at $1 \mu \mathrm{m}$ with glass knives and mounted onto gelatin-coated slides. F or each eyecup, 50-70 sections were collected, 10 sections per slide. The sections on the first and last slide from each eyecup were stained with toluidine blue, coverslipped and used for aligning the sections when the lightly-stained, emulsion-coated slides were quantitatively analyzed (see below).

Unstained slides were dipped in NTB-2 liquid emulsion (Kodak, Rochester, NY), dried at room temperature and stored in the dark at $4^{\circ} \mathrm{C}$. Slides were developed in Kodak D-19, rinsed extensively, lightly counterstained with dilute toluidine blue, dried, and coverslipped. Test slides were developed from 4 days to 4 weeks to determine the rate of silver grain formation, which was estimated by counting silver grains overlying the inner plexiform layer (IPL). This preliminary study established that an exposure of two and one-half weeks both gave a robust signal and was within the linear range of silver grain formation.

\section{I maging and quantitative analysis}

Digital images of either the differentiated retina or CGZ were captured by using a CCD camera (Optronics Engineering, Schaumburg, IL) attached to an Olympus Vannox microscope. The program Capture+ (TruVision, I ndianapolis, IN) was used to capture images in an 8-bit format, which facilitated image analysis when imported into $\mathrm{NIH}$ Image (v. 1.59 or 1.60; available on the Internet by accessing the $\mathrm{NIH} \mathrm{I} \mathrm{mage} \mathrm{homepage,} \mathrm{http://rsb.info.nih.gov/}$ nih-image/). Images from six sections per eyecup (18 sections total) were used for quantitative analysis.

Custom macros and NIH I mage were used to facilitate the repetitive image processing and analysis. I mages were converted to grayscale, thresholded by using the threshold function within $\mathrm{NIH}$ Image (which effectively removed from the image the lightly stained cells beneath the silver grains) and saved as black and white, binary images. Depending on whether the differentiated retina or CGZ was analyzed, one of two macros were used to make the quantitative measurements on the binary images. Data files wereanalyzed by using a spreadsheet program (Microsoft Excel, v. 5.0).

Images of the differentiated retina were taken from locations corresponding to the mature neural retina (MNR), as described previously (Boucher and Hitchcock, 1998). To quantify the [125] -IGF-I binding in the differentiated retina, scatter plots were generated of the distribution of black pixels (i.e., silver grains in the emulsion) from the outer limiting membrane (OLM) to the inner limiting membrane (ILM). NIH I mage generates scatter plots by scanning and counting black pixels from left to right in a 480-pixel tall by 1-pixel wide bar in single pixel increments. The number of black pixels in each scan (each 
section) was divided into twenty bins. The first bin overlay the OLM; the last bin overlay the ILM. For the six scans from each retina, the number of black pixels per bin was averaged. These values were then averaged for the three retinas used in each condition. The mean and standard error of each bin was graphed as a linear plot from 0 to $100 \%$ retinal thickness, where $0 \%$ represents the OLM and $100 \%$ represents the I LM . A time-set, repeated measures ANOVA was performed to compare the plot of the average number of silver grains overlying the IPL. This tests the null hypothesis that the two linear plots compared are parallel. $P$ values equal to or less than 0.05 were considered statistically significant.

To quantify the [125I]-IGF-I binding in the CGZ of each eye, a template was created by outlining the CGZ in an image from a normally-stained section and aligning the template with the image of the CGZ from the nearby, lightly stained sections processed for emulsion autoradiography. Use of a template was necessary, because lightly staining the sections, which was necessary to adequately threshold theimages (seeabove), made defining the boundary of the CGZ problematic. The criteria for identifying the boundary of the CGZ were similar to those described in the previous paper (Boucher and Hitchcock, 1998). Within the template, the average size of a silver grain (expressed as pixels) was calculated, and the total number of silver grains overlying the CGZ was determined and expressed as the number of silver grains per $1,000 \mu \mathrm{m}^{2}$. The density of silver grains overlying the CGZ was averaged for six sections from each eye, and these averages were combined as described above. A two-sample Student t-test was performed on the means. $P$ values equal to or less than 0.05 were considered statistically significant.

\section{RE SULTS \\ [125I]-I GF -I has specific binding sites in the goldfish retina}

[125I]-IGF-I bound within two specific regions of the retina, the inner plexiform layer and the CGZ (Fig 1).

In the differentiated retina, silver grains overlay the inner half of the retina, from the boundary between the INL and IPL (approximately 50\% of retinal thickness) to the inner limiting membrane (Fig. 1A). The plot of silver grains peaked over the inner $1 / 3$ of the IPL (approximately $80 \%$ of retinal thickness). There were no focal clusters of silver grains overlying individual ganglion cell somata, therefore it is assumed that the [125] ]-IGF-I was bound only to processes within the IPL. In the outer half of the retina, from IPL to the OLM, the number of silver grains was at background levels, and there were no clusters of grains overlying somata in either the INL or ONL. In some eyes, however, there was a small elevation in the number of silver grains around $25 \%$ of the retinal thickness, roughly centered over the outer plexiform layer (Fig. 1A). At the margin of the retina, the silver grains overlying the IPL terminated in a relatively dense cluster of silver grains overlying the CGZ (Fig. 1B).

Experiments that included unlabeled molecules as competitive inhibitors modulated the pattern and levels of binding by [125I ]-I GF -I (Figs. 2-4).

Addition of 100-fold excess of unlabeled IGF-I significantly inhibited binding by the [125I]-IGF-I, markedly reducing the number of silver grains overlying the IPL and CGZ, (Figs. 2, 3A, 4). Treatment with 100-fold excess
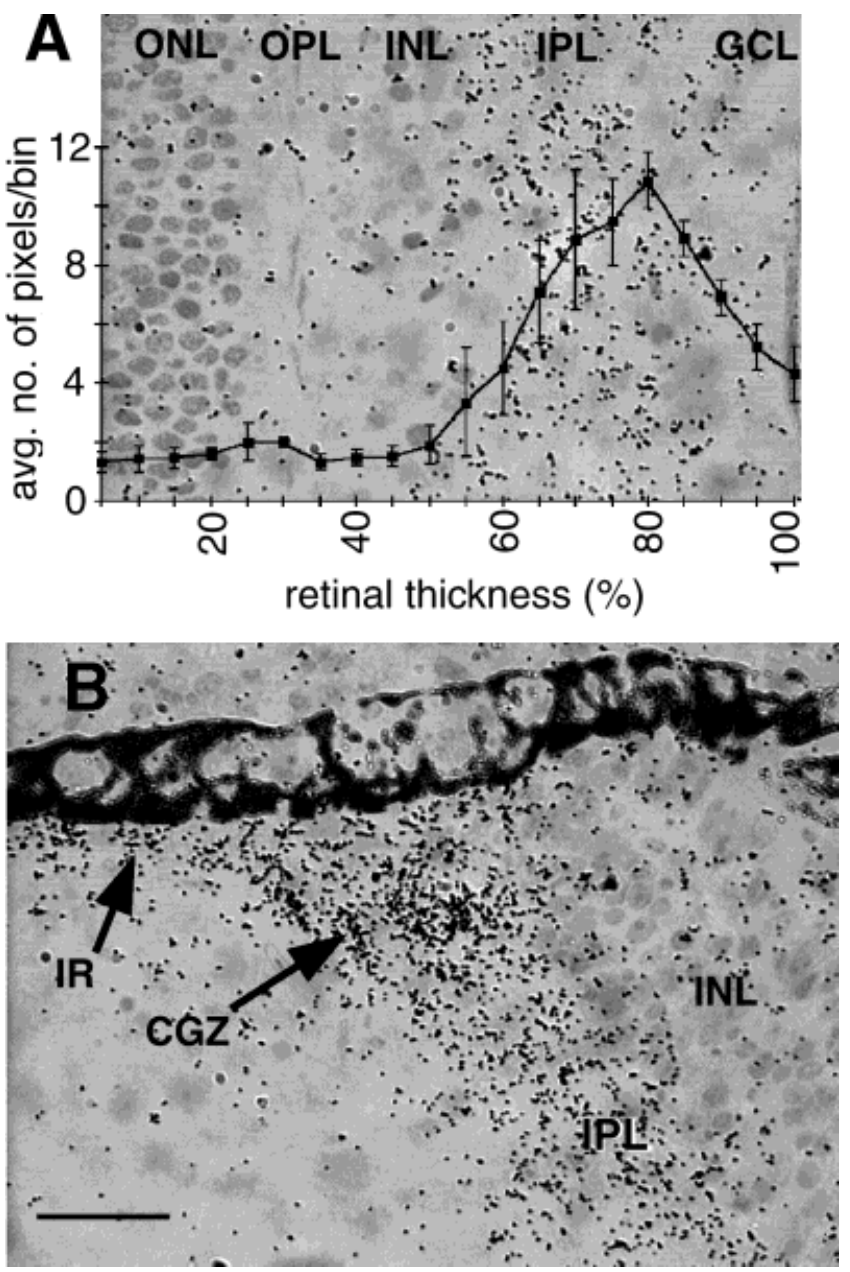

Fig. 1. Digital images of sections taken from a retina incubated with 5 nM [125I]-IGF-I. A: Plot of the average number of silver grains overlying the differentiated retina superimposed on a corresponding image of the retina. B: Digital image of the CGZ and adjacent differentiated retina with silver grains overlying the IPL and CGZ. IGF-I, Insulin-like growth factor; ONL, outer nuclear layer; OPL, outer plexiform layer; INL, inner nuclear layer; IPL, inner plexiform layer; GCL, ganglion cell layer; CGZ, circumferential germinal zone; IR, iris epithelium. Scale bar $=25 \mu \mathrm{m}$.

unlabeled IGF-II was slightly less effective in competing for the binding sites of [125I]-IGF-I within the IPL (Fig. 3B). However, unlabeled IGF-II reduced the density of silver grains overlying the CGZ to the same degree as the unlabeled IGF-I (Fig. 4). Unlabeled insulin did not inhibit the binding of [125| ]-IGF-I in the IPL or CGZ (Figs. 3C, 4). This combination of results indicates that the radiolabeled IGF -I was binding at sites specific for the IGF-I peptide.

\section{des-(1-3)-I GF -I partially inhibits binding by $\left[{ }^{125} I\right]-I G F-I$}

des-(1-3)-IGF-I is a naturally occurring variant of mammalian IGF-I in which the first three amino acids are absent from the $\mathrm{N}$-terminus (Ballard et al., 1996). This post-translational modification does not alter the peptide's affinity for the IGF-I receptor, but does result in a 40-fold decrease in its affinity for IGF-I binding proteins. 


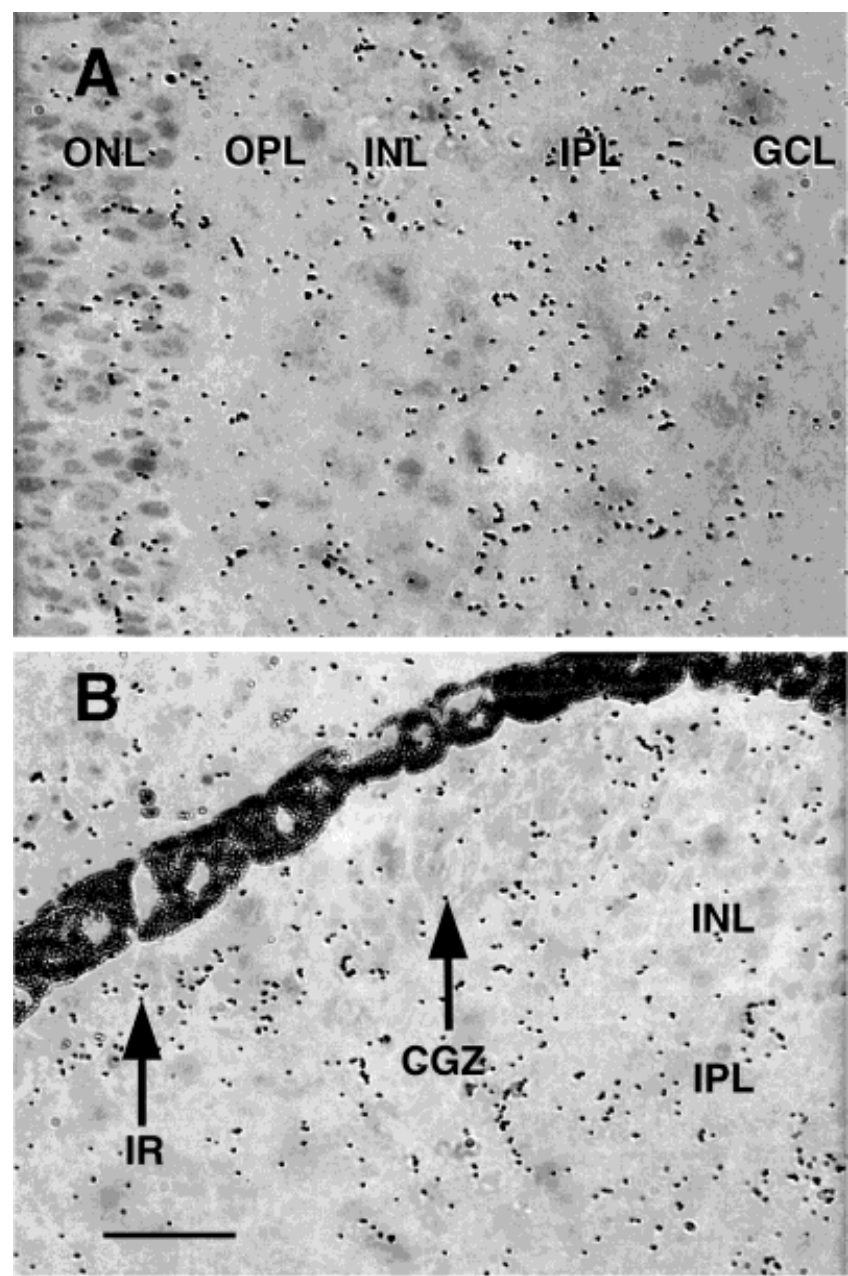

Fig. 2. Digital photomicrographs of sections taken from a retina incubated with $5 \mathrm{nM}$ [125I]-IGF-I and $500 \mathrm{~nm}$ unlabeled IGF-I. A: The differentiated retina. B: The CGZ and adjacent differentiated retina. Note the absence of a distinct pattern of silver grains overlying the retina (cf. Figs. 1 and 2). ONL, Outer nuclear layer; I NL, inner nuclear Iayer; CGZ, circumferential germinal zone (arrow); IR, iris epithelium (arrow). Scale bar $=25 \mu \mathrm{m}$.

Although we had no a priori knowledge about the affinity of mammalian des-(1-3)-IGF-I for teleost IGF-I receptors and binding proteins, we tested this molecule nonetheless in an attempt to further characterize the IGF-I binding sites in the retina of the goldfish. I f des-(1-3)IGF-I has similar affinities for binding proteins in teleost and mammalian tissues, it should effectively compete with [125I]-IGF-I for binding to the IGF-I receptor but not for binding to the binding proteins. In this experiment residual silver grains overlying either the IPL or CGZ should be due to [125I]-IGF-I binding to IGF-binding proteins. A 30-fold excess of des-(1-3)-IGF-I was used, based on an estimate that this concentration should effectively compete with the binding of [125I]-IGF-I at the IGF-IR but not compete for binding at IGF-BPs (see Carlsson-Skwirut et al., 1989; Ogasawara et al., 1989; Oh et al., 1993). The addition of unlabeled des-(1-3)-IGF-I decreased, but did not eliminate binding of [125] ]-IGF-I within the IPL (Fig. 5B). In contrast, the des-(1-3)-IGF-I completely inhibited the binding of [125I]-IGF-I to the neuronal progenitors
A

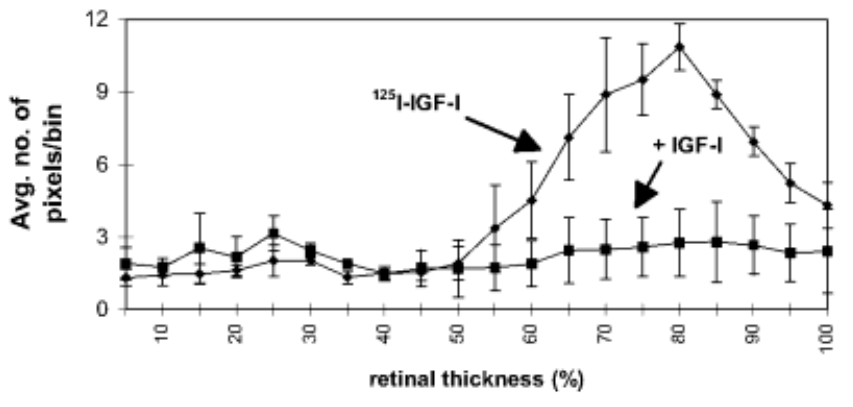

B

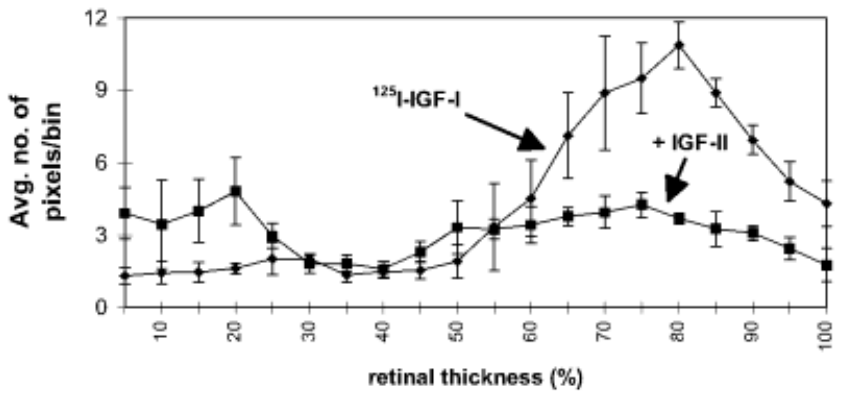

C

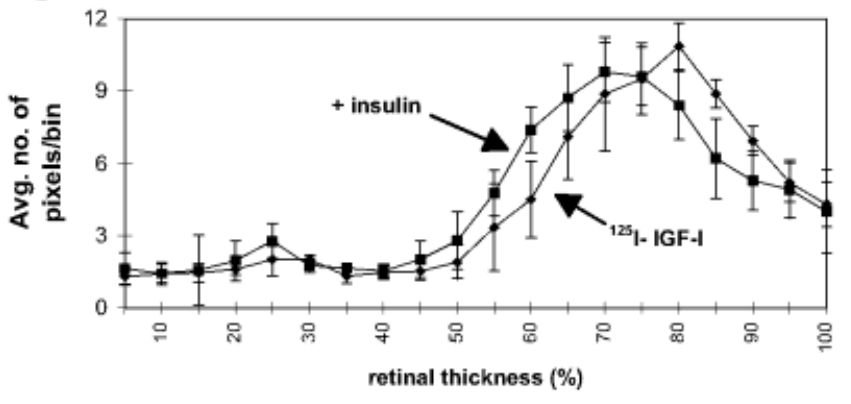

Fig. 3. Competitive inhibition of [ ${ }^{125}$ ] ]-insulin-like growth factor 1 (IGF-I) binding to the differentiated retina. Each panel includes the plot of the average number of pixels overlying sections from eyecups incubated with $5 \mathrm{nM}$ [125I]-IGF-I alone (closed diamonds). Remaining pl ots illustrate the average number of pixels (i.e., silver grains) per bin in sections of the differentiated retina incubated with $5 \mathrm{~nm}$ [125I ]-I GF-I and: A: 500 nM IGF-I (closed squares), B: 500 nM IGF-II (closed squares), or C: $500 \mathrm{nM}$ insulin (closed squares). Statistical comparisons demonstrated that unlabeled IGF-I and IGF-II significantly inhibited binding by the labeled IGF-I, whereas unlabeled insulin did not. (In B, there was an apparent elevation in the average number of silver grains overlying the outer nuclear layer in retinas in which IGF-II was added as a competitive inhibitor [also see Fig. 5B]. This was not observed in retinas treated with label ed IGF-I alone or retinas treated with labeled IGF-I and unlabeled I GF-I and unlabeled insulin. We believe this to be artifact, although its source is not apparent.)

within the CGZ (Figs. 4 and 5A). These results suggests that within the goldfish retina the I PL contains both I GF -I receptors and IGF-binding proteins, whereas within the CGZ only receptors are present.

\section{DISCUSSION}

IGF-I, IGF-IR, and IGF-BPs constitute a family of cellular modulators critical for the normal growth and 


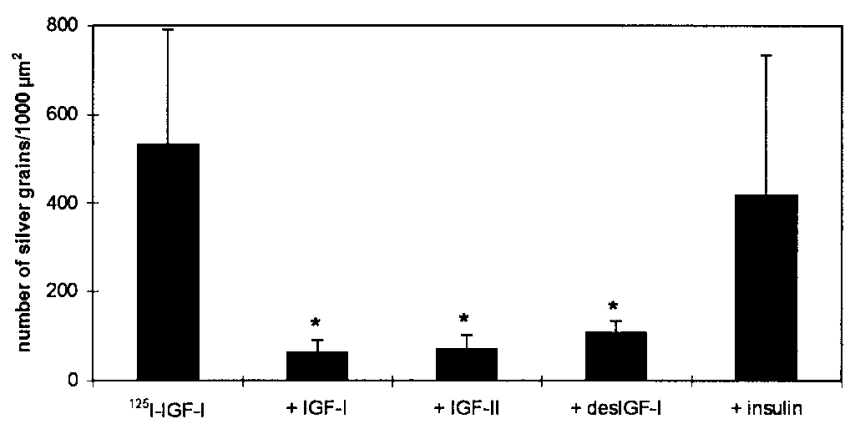

Fig. 4. [125I]-insulin-like growth factor 1 (IGF-I) binding to the CGZ. Each bar represents the density of silver grains overlying the CGZ in separateincubation conditions: $5 \mathrm{nM}$ [125/ ]-IGF-I al one or $5 \mathrm{nM}$ [125I]-IGF-I plus unlabeled IGF-I (+IGF-I), IGF-II (+IGF-II), des-(1-3)IGF-I (+des-(1-3)-IGF-I), and insulin (+insulin). The addition of unlabeled IGF-I, I GF-II and des-(1-3)-IGF-I significantly inhibited the binding of the labeled IGF-I. Asterisk indicates $\mathrm{P}<0.05$.

development of the central nervous system (de Pablo and dela Rosa, 1995; D'E rcole et al., 1996). In primary cultures of embryonic neuronal progenitors and neurons, IGF-I can stimulate proliferation, survival, differentiation, process outgrowth, and synaptogenesis (de Pablo and de la Rosa, 1995; D'E rcole et al., 1996). In addition to the effects on somatic growth, mice with targeted deletions of IGF-I or the IGF-IR develop abnormally small brains and regionspecific deficits in the organization of both gray and white matter (Liu et al., 1993), whereas mice overexpressing I GF -I show selective, hypertophic brain growth (Carson et al., 1993; Ye et al., 1996). In the adult brain I GF-I may act as a neuromodulator, a neurotrophin and a regulator of CNS metabolism (Folli et al., 1996; Doré et al., 1997).

From results described in the previous paper (Boucher and Hitchcock, 1998), we hypothesized that IGF-I and its receptor regulate the mitotic activity of the retinal progenitors within the CGZ. In the present study, we tested this hypothesis, in part, by performing receptor-binding autoradiography to determine the distribution and specificity of binding sites for IGF-I in the retina of the adult goldfish. The data showed that [125I]-IGF-I binds within the IPL of the mature, differentiated retina and to the neuronal progenitors within the CGZ. Unlabeled IGF-I and IGF-II competitively inhibited binding by [125] ]-IGF-I, whereas unlabeled insulin did not. The effectiveness of the competitive inhibitors at displacing the radiolabeled IGF-I is consistent with the well characterized differences in the affinities of IGF-IR and the IGF-BPs for IGF-I, IGF-II, and insulin in both mammals (V ones and Clemmons, 1995) and fish (Parrizas et al., 1995) and confirms that the binding of the [125I]-IGF-I was at sites specific for IGF-I. (A recent study suggests that teleosts lack receptors specific for IGF-II [Drakenberg et al., 1993].) The results from experiments using des-(1-3)-IGF-I as a competitive inhibitor suggest that the IPL contains both IGF-I receptors and IGF-I binding proteins, whereas binding proteins are not present within the CGZ.

It is well documented that the family of IGF-I molecules is present in the developing and mature retina (see de Pablo and de la Rosa, 1995). In the embryonic retina of mammals and birds, IGF-I is synthesized first by neuronal progenitors (e.g., Hernández-Sánchez et al., 1995; F rade et al., 1996) and then in differentiated neurons within the

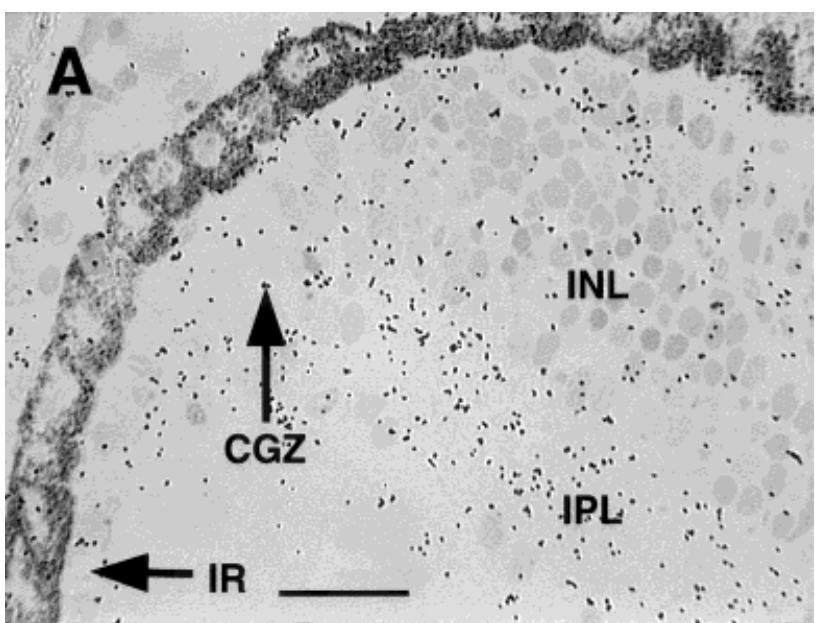

B

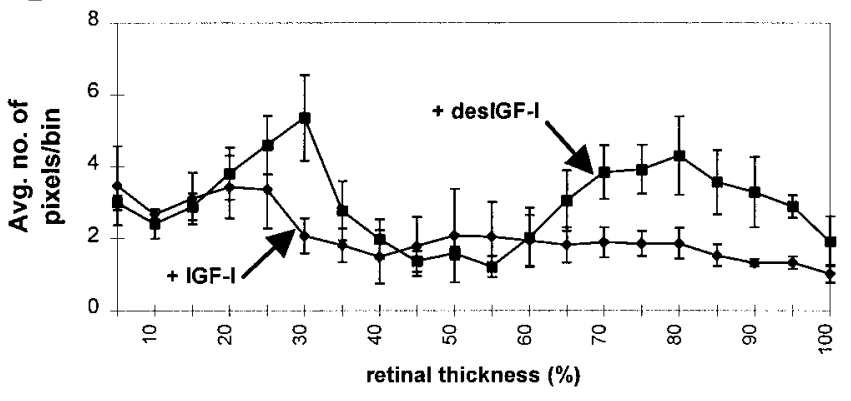

Fig. 5. Digital image of a section from a retina incubated with $5 \mathrm{nM}$ [125I]-insulin-like growth factor 1 (IGF-I) and unlabeled des-(1-3)IGF-I. A: The CGZ and the adjacent differentiated retina. B: Plot of the average number of pixels per bin for sections from retinas treated with [125I]-IGF-I and unlabeled des-(1-3)-IGF-I (closed squares). A plot illustrating retinas treated in the same experiment with [125] ]-IGF-I and unlabeled IGF-I (closed diamonds) is included for comparison. Note the elevated average number of silver grains at 30\% retinal thickness, which was present only in the retinas treated with des-(1-3)IGF-I. ONL, Outer nuclear layer; INL, inner nuclear layer; IPL, inner plexiform layer; CGZ, circumferential germinal zone; IR, iris epithe lium. Scale bar $=25 \mu \mathrm{m}$.

ganglion cell layer (de la Rosa et al., 1994), a pattern of expression that persists in the adult (Burren et al., 1996). The IGF-IR and IGF-BPs follow similar patterns of expression, as demonstrated by both binding autoradiography and in situ hybridization with IGF-IR probes. During midstage retinal differentiation in the chick, IGF-I binding, mediated by IGF-I receptors (see Waldbillig et al., 1991; de la Rosa et al., 1994; Hernández-Sánchez et al., 1995), is present in the proliferating neuroepithelium and, as development proceeds and cellular differentiation ensues, the binding becomes restricted to the plexiform layers (Bassas et al., 1989; Bassnett and Beebe, 1990; although see Ocrant et al., 1989). Messenger RNA for the IGF-I receptor is present in the neuroblastic layer in the embryonic rat (Lee et al., 1992), in post-mitotic neurons in the embryonic chick (Holzenberger et al., 1996) and in the ganglion cell and inner nudear layers in the adult rat (Burren et al., 1996). The spatial pattern of IGF-I binding in the goldfish is consistent with the developmental patterns of I GF-I R expression and receptor binding autoradiography observed in mammals and birds. Although we 
have not demonstrated here the presence of IGF -I within the goldfish retina, the coordinate expression of IGF -I and the IGF-IR in the mammalian brain (Bondy et al., 1992; Lee et al., 1992) suggests that in the goldfish the neuronal progenitors of the CGZ and neurons in the ganglion cell and/or inner nuclear layers are likely to synthesize and release IGF-I (although see Mack et al., 1995).

The most well documented signaling function of the IGF-I and its receptor is regulating cell proliferation (J ones and Clemmons, 1995). I GF-I is mitogenic for a wide spectrum of cell types, including neuronal progenitors in the brain (D'Ercole et al., 1996; Folli et al., 1996) and retina (e.g., Hitchcock and Boucher, 1998). In contrast to this role, there is no similarly obvious function for IGF-I and its receptor in the differentiated retina. One possibility is that in differentiated retina, IGF-I also acts as a mitogen, although we observed no evidence of this in the previous study. IGF-I stimulates proliferation of adult Müller cells, specialized retinal glia, isolated from human retinas (I keda et al., 1995) and rod precursors in the mature retina of the chiclid fish Haplocromis burtoni (Mack and Fernald, 1993; see also Mack et al., 1995; Hoke and Fernald, 1997). A second possibility is that in the differentiated retina of the goldfish, IGF-I plays a role in regulating neuronal growth and synaptogenesis. In the developing CNS, the highest expression of IGF-I message occurs during the later stages of neuronal development, coincident with neuronal differentiation, process outgrowth, and synaptogenesis (de Pablo and de la Rosa, 1995). In the goldfish, extant retinal neurons grow continually, by increasing their size (Kock, 1982; Hitchcock and Easter, 1986), complexity (Kock and Stell, 1985; Brown and Hitchcock, 1989) and the number of synaptic contacts they make (Fisher and Easter, 1979). IGF-I and the IGF-IR could regulate this continual neuronal growth, which resembles some aspects the late embryonic growth in the CNS of other vertebrates. Although we cannot assign a function to IGF-I in the differentiated retina, preliminary experiments in our lab (Boucher and Hitchcock, unpublished observations) indicate that in the isolated goldfish retina IGF-I stimulates a rapid (within 1 minute) tyrosine phosphorylation of a protein whose apparent molecular weight is similar to that for the $\beta$ subunit of the IGF-I receptor. This suggests that the signal transduction pathways activated by IGF-I are present in the retina of the adult goldfish, although the cellular events regulated there by IGF-I and the IGF-IR are not yet known.

In light of our studies (Boucher and Hitchcock, 1998; see Results), we make the following three speculations: 1) In the adult goldfish IGF-I and the IGF-IR regulate the ongoing proliferation of the retinal progenitors in the CGZ, which is coordinated with the continual growth of the retina, other ocular components and other organs. This growth-associated mitotic activity is influenced by factors such as environmental stress and the nutritional status of the animal and is regulated by circulating levels of IGF-I (regulated by growth hormone), retinal levels of IGF-I or both (see Duan, 1998). 2) The production of rod photoreceptors is not regulated by IGF-I (these cells should not express the IGF-IR), but is under the control of yet-to-beidentified molecule(s), perhaps resident in the outer nuclear layer (see Raymond et al., 1988). 3) Although we have inferred from previous studies that retinal regeneration recapitulates retinal development (e.g., Hitchcock et al., 1996; see also Sullivan et al., 1997), the molecules that regulate injury-stimulated neurogenesis within the blastema differ from those that regulate growth-related neurogenesis within the CGZ. This implies that at least two different molecules in the goldfish retina have the ability to modulate mitotic activity of multipotent retinal progenitors. One of these molecules is likely synthesized by neurons in the outer retina (Raymond et al., 1988), released locally by their destruction and stimulates prol iferation and neurogenesis in the blastema, whereas the other, and we suggest this molecule is IGF-I, is present in the CGZ, modulates neurogenesis among these cells and is regulated by factors that coordinate animal growth.

\section{ACKNOWLE DGME NTS}

The authors thank Drs. C. Duan and A. D'Costa and Ms. D. Otteson for critically reading earlier versions of this paper, Drs. D. Musch and K. Guire for help with the statistical analyses, P. Cirenza and M. Gillett for technical assistance, and D. Giebel for secretarial assistance.

\section{LITERATURE CITED}

Ballard, F.J ., J .C. Wallace, G.L. Francis, L.C. Read, and F.M. Tomas (1996) Des(1-3)IGF-I: A truncated form of insulin-like growth factor-I. Int. J . Biochem. Cell Biol. 28:1085-1087.

Bassas, L., M. Girbau, M.A. Lesniak, J. Roth, and F. de Pablo (1989) Development of receptors for insulin and insulin-like growth factor-I in head and brain of chick embryos: Autoradiographic localization. Endocrinol ogy 125:2320-2327.

Bassnett, S., and D.C. Beebe (1990) Localization of insulin-like growth factor-1 binding sites in the embryonic chicken eye. I nvest. Ophthalmol. Vis. Sci. 31:1637-1643.

Bondy, C., H. Werner, C.T. Roberts, J r., and D. LeRoith (1992) Cellular pattern of type-1 insulin-like growth factor receptor gene expression during maturation of the rat brain: Comparison with insulin-like growth factors I and II. Neuroscience 46:909-923.

Boucher, S.-E.M. and P.F. Hitchcock (1996) Insulin-like growth factor I (IGF-I) binding in the adult goldfish retina. Soc. Neurosci. 22:1979.

Boucher, S.-E.M. and P.F. Hitchcock (1998) Insulin-related growth factors stimulate proliferation of multipotent neuronal progenitors in the retina of the goldfish. J . Comp. Neurol. 394:386-394.

Brown, R.N., I r. and P.F. Hitchcock (1989) Dendritic growth of DAPIaccumulating amacrine cells in the retina of the goldfish. Dev. Brain Res. 50:123-128.

Burren, C.P., J L. Berka, S.R. Edmondson, G.A. Werther, and J .A. Batch (1996) Localization of mRNAs for insulin-like growth factor-I (IGF-I), IGF-I receptor, and IGF binding proteins in rat eye. Invest Ophthalmol. Vis. Sci. 37:1459-1468.

Calvaruso, G., R. Vento, M. Giuliano, M. Lauricella, E. Gerbino, and G. Tesoriere (1996) Insulin-like growth factors in chick embryo retina during development. Regul. Pept. 61:19-25.

Carlsson-Skwirut, C., M. Lake, M. Hartmanis, K. Hall, K., and V.R. Sara (1989) A comparison of the biological activity of the recombinant intact and truncated insulin-like growth factor 1 (IGF-I). Biochem. Biophys. Acta. 1011:192-197.

Carson, M.J ., R.R. Behringer, R.L. Brinster, and F.A. McMorris (1993) Insulin-like growth factor I increases brain growth and central nervous system myelination in transgenic mice. Neuron 10:729-740.

Chan, S.J ., S. Nagamatsu, Q.P. Cao, and D.F. Steiner (1992) Structure and evolution of insulin and insulin-like growth factors in chordates. Prog. Brain Res. 92:15-24.

de la Rosa, E.J ., C.A. Bondy, C. Hernández-Sánchez, X. Wu, J. Zhou, A. Lopez-Carranza, L.M. Scavo, and F. de Pablo (1994) Insulin and insulin-like growth factor system components gene expression in the chicken retina from early neurogenesis until late development and their effect on neuroepithelial cells. Eur.J . Neurosci. 6:1801-1810.

de Pablo, F. and E.J . de la Rosa (1995) The developing CNS: a scenario for the action of proinsulin, insulin and insulin-like growth factors. Trends Neurosci. 18:143-150.

D'Ercole, J .A., Y. Ping, A.S. Calikoglu, and G. Gutierrez-Ospina (1996) The role of insulin-like growth factors in the central nervous system. Mol. Neurobiol. 13:227-255. 
Doré, S., S. Kar, and R. Quirion (1997) Rediscovering an old friend, IGF-I: Potential use in the treatment of neurodegenerative diseases. Trends Neurosci. 20:326-331.

Drakenberg, K., V.R. Sara, S. Falkmer, S. Gammeltoft, C. Maake, and M. Reinecke (1993) Identification of IGF-1 receptors in primitive verte brates. Regul. Pept. 43:73-81.

Duan, C. (1998) Nutritional and developmental regulation of insulin-like growth factors in fish. J . Nutrition. 128:306S-314S.

Fisher, L.J . and S.S. Easter, J r. (1979) Retinal synaptic arrays: continuing devel opment in the adult goldfish. J . Comp. Neurol. 185:373-379.

Folli, F., S. Ghidella, L. Bonfanti, C.R. Kahn, and A. Merighi (1996) The early intracellular signaling pathway for the insulin/insulin-like growth factor receptor family in the mammalian central nervous system. Mol. Neurobiol. 13:155-183.

Frade, J.M., E. Martí, P., Bovolenta, M. Ángeles Rodríguez-Peña, D. Pérez-Garcia, H. Rohrer, D. Edgar, and A. Rodríguez-Tébar (1996) Insulin-like growth factor-I stimulates neurogenesis in chick retina by regulating expression of the $\alpha 6$ integrin subunit. Development 122:24972506.

Hernández-Sánchez, C., A. López-Carranza, C. Alarcón, E.J . de La Rosa and F. de Pablo (1995) Autocrine/paracrine role of insulin-related growth factors in neurogenesis: Local expression and effects on cell proliferation and differentiation in retina. Proc. Natl. Acad. Sci. USA 92:9834-9838.

Hitchcock, P.F. and S.S. Easter, J r. (1986) Retinal ganglion cells in goldfish A qualitative classification of four morphological types, and a quantitative study of the development of one of them. J . Neurosci. 6:1037-1050.

Hitchcock, P.F., R.E. Macdonald, J .T. VanDeRyt, and S.W. Wilson (1996) Antibodies against Pax6 immunostain amacrine and ganglion cells and neuronal progenitors, but not rod precursors, in the normal and regenerating retina of the goldfish. J. Neurobiol. 29:399-413.

Hoke, K.L. and R.D. Fernald (1997) Rod photoreceptor neurogenesis. Prog. Retinal Res. 16:31-49.

Holzenberger, M. F. Lapointe, M. Leibovici, and C. Ayer-Le Lièvre (1996) The avian I GF-type 1 receptor: CDNA analysis and in situ hybridization reveal conserved sequence elements and expression patterns relevant for the development of the nervous system. Dev. Brain Res. 97:76-87.

I keda, T., R.J . Waldbillig, and D.G. Puro (1995) Truncation of IGF-I yields two mitogens for retinal Müller glial cells. Brain Res. 686:87-92.

J ones, J .I . and D.R. Clemmons (1995) Insulin-like growth factors and their binding proteins: Biological actions. Endocrine Rev. 16:3-34.

Kock, J.-H. (1982) Dendritic tree structure and dendritic hypertrophy during growth of the crucian carp eye. J . Comp. Neurol. 209:264-274.

Kock, J.-H. and W.K. Stell (1985) Formation of new rod photorecepto synapses onto differentiated bipolar cells in goldfish retina. Anat. Rec. 211:69-74

Lee, W.H., S. J avedan, and C.A. Bondy (1992) Coordinate expression of insulin-like growth factor system components by neurons and neuroglia during retinal and cerebellar development. J . Neurosci. 12:4737-4744.

Leibush, B., M. Parrizas, I. Navarro, Y. Lappova, M.A. Maestro, M. Encinas, E.M. Plisetskaya, and J . Gutiérez (1996) Insulin and insulinlike growth factor-I receptors in fish brain. Regul. Pept. 61:155-1561.

Liu, X., J . Baker, A.S. Perkins, E.J . Robertson, and A. Efstratiadis (1993) Mice carrying null mutations of the genes encoding insulin-like growth factor I (I gf-1) and type 1 I GF receptor. Cell 75:59-72.
Mack, A.F. and R.D. Fernald (1993) Regulation of cell division and rod differentiation in the teleost retina. Dev. Brain Res. 76:183-187.

Mack, A.F., S.L. Balt, and R.D. Fernald (1995) Localization and expression of insulin-like growth factor in the teleost retina. Vis. Neurosci. 12:457-461.

Ocrant, I., K.L. Valentino, M.G. King, T.H. Wimpy, R.G. Rosenfeld, and D.G. Baskin (1989) Localization and structural characterization of insulinlike growth factor receptors in mammalian retina. Endocrinology 125:2407-2413.

Ogasawara, M., K.P. Karey, H. Marquardt, and D.A. Sirbasku (1989) Identification and purification of truncated insulin-like growth factor I from porcine uterus: Evidence for high biological potency. Biochemistry 28:2710-2721.

Oh, Y.H.L., Muller, D.-Y. Lee, P.J . Fielder, and R.G. Rosenfeld (1993) Characterization of the affinities of insulin-like growth factor (IGF)binding proteins 1-4 for IGF-I, I GF-II, IGF-I/I nsulin hybrid, and IGF-I analogs. Endocrinology 132:1337-1344.

Parrizas, M., E.M. Plisetskaya, J . Planas, and J . Gutierrez (1995) Abundant insulin-like growth factor-1 (IGF-I) receptor binding in fish skeletal muscle. Gen. Comp. Endocrinol. 98:16-25.

Raymond, P.A., M.J. Reifler, and P.K. Rivlin (1988) Regeneration of the goldfish retina: rod precursors are a likely source of regenerated cells. J . Neurobiol. 19:431-463.

Reinecke, M., D. Betzler, K. Drakenberg, S. Falkmer, and V.R. Sara (1993) Occurrence of members of the insulin superfamily in central nervous system and digestive tract of protocordates. Histochemistry 99:277285

Richardson, N.A., A.J. Anderson, M.A. Rimmer, and V.R. Sara (1995) Localization of insulin-like growth factor-I immunoreactivity in larval and juvenile barramundi (Lates calcarifer). Gen. Comp. Endocrinol. 100:282-292.

Schoen, T.J ., D.C. Beebe, D.R. Clemmons, G.J . Chader, and R.J . Waldbillig (1992) Local synthesis and developmental regulation of avian vitreal insulin-like growth factor-binding proteins: a model for independent regulation in extravascular and vascular compartments. Endocrinology 131:2846-2854.

Sullivan, S.A., L.K. Barthel, B.L. Largent, and P.A. Raymond (1997) A goldfish Notch-3 homologue is expressed in neurogenic regions of embryonic, adult, and regenerating brain and retina. Dev. Gen. 20:208223.

Thorndyke, M.C., D. Purvis, and E.M. Plisetskaya (1989) Insulin-like immunoreactivity in the brain of two hagfishes, Eptatretus stouti and Myxineglutinosa. Gen. Comp. Endocrinol. 76:371-381.

Waldbillig, R.J ., D.R. Arnold, R.T. Fletcher, and G.J . Chader (1991) Insulin and IGF-I binding in developing chick neural retina and pigment epithelium: A characterization of binding and structural differences. Exp. Eye. Res. 53:13-22.

Yang, Y.W., D.R. Brown, H.L. Robcis, M.M. Rechler, and F. de Pablo (1993) Developmental regulation of insulin-like growth factor binding protein-2 in chick embryo serum and vitreous humor. Regul. Pept. 48:145155

Ye, P., Xing, Y., Dai, Z., and J . D'Ercole (1996) In vivo actions of insulin-like growth factor I (IGF-I) on cerebellum development in transgenic mice: Evidence that IGF-I increases proliferation of granule cells. Dev. Brain Res. 95:44-54. 